\title{
Sistema computacional aplicado ao cálculo da demanda hídrica georeferenciada para a cultura do feijão ${ }^{1}$
}

Francisco S. Dantas Neto ${ }^{2}$, José M. N. da Costa ${ }^{3}$, Antonio A. Soares ${ }^{3}$, Gilberto C. Sediyama ${ }^{3}$, Luiz C. Costa ${ }^{3}$

\author{
1 Parte da dissertação de Mestrado do primeiro autor apresentada na UFV \\ 2 DEA/ESAM, C.P. 137, CEP 59625-900, Mossoró, RN. Fone:(84) 3317-0004. E-mail: solon@esam.br (Foto) \\ 3 DEA/UFV. CEP 36571-000, Visoça, MG. E-mail: jmncosta@ufv.br; ralves@ufv.br; sediyama@ufv.br; I.costa@ufv.br
}

Protocolo 120 - 23/8/2002 - Aprovado em 28/10/2004

\begin{abstract}
Resumo: Para se determinar as demandas de irrigação e as melhores datas para o plantio da cultura do feijoeiro na bacia dos Rios do Leste, implementou-se um programa computacional, denominado DEMANDAsis, que se baseia no balanço de água no solo, consistindo de um sistema composto por programas e bancos de dados. Os resultados sobre datas propícias ao plantio do feijão na bacia dos Rios do Leste indicaram que o período entre 5 e 19 de outubro é o que assegura maior disponibilidade de água de origem pluvial durante o ciclo da cultura, em cerca de $53 \%$ da área da bacia. A aplicação de lâminas de irrigação suplementar de 4 a $5 \mathrm{~mm} \mathrm{~d}^{-1}$ foi considerada adequada em torno de $40 \%$ da área da bacia.
\end{abstract}

Palavras-chave: DEMANDAsis, balanço de água no solo, datas de plantio do feijão

\section{Calculation of georeferenced water demand for a bean crop: A computational system}

\begin{abstract}
A computational program was implemented to determine the irrigation requirements and the best planting dates of bean crop at the Rios do Leste Watershed. The program, called DEMANDAsis, is based on a soil water balance, consisting of computational programs and databases. The results about the best planting dates of bean crop at Rios do Leste Watershed showed that the period between $5^{\text {th }}$ and $19^{\text {th }}$ October assures greater availability of rainfall during the growing cycle of the crop in about $53 \%$ of the area of the basin. The use of supplemental irrigation of 4 to $5 \mathrm{~mm} \mathrm{~d}^{-1}$ was considered to be adequate in about $40 \%$ of the area of the watershed.
\end{abstract}

Key words: DEMANDAsis, soil water balance, bean planting date

\section{INTRODUÇÃO}

O conhecimento sobre o processo de retenção de água no solo e demanda hídrica das culturas é fundamental para o dimensionamento e manejo de sistemas de irrigação. Segundo Faria (1998), conhecendo-se o consumo de água da cultura e levando em consideração a contribuição das chuvas e as perdas operacionais, é possível dimensionar adequadamente a rede hidráulica de um projeto de irrigação, como os canais, as tubulações, os reservatórios e a estação de bombeamento. Conforme Reichardt (2004) do ponto de vista agronômico o balanço de água no solo define as condições hídricas sob as quais uma cultura está submetida.

A utilização de ferramentas computacionais usadas para auxiliar no planejamento e tomada de decisão na agricultura, possibilitam a realização de simulações para variados cenários, baseados em parâmetros locais, gerando resultados úteis para o planejamento das atividades agrícolas. De acordo com Marouelli (1993) os modelos de balanço de água no solo podem ser estruturados através de programas computacionais e trazer informações de ganho, perda e armazenamento de água no solo, sendo de grande utilidade para determinação da irrigação.

Muitos modelos de simulação computacional (Costa et al., 1997; Souza, 1993; Smith, 1992) têm sido propostos com base no balanço de água no solo para determinar as necessidades de água das culturas. A utilização de sistemas computacionais que atuem na estimativa de necessidades hídricas ou que estejam embutidos na estrutura dos modelos de simulação, é uma alternativa necessária para o monitoramento de áreas irrigadas, visando dar sustentabilidade à irrigação e 
gerenciamento eficiente e racional ao uso dos recursos hídricos de uma região.

Este trabalho teve como objetivo implementar um sistema computacional baseado num balanço de água do solo, para determinar as demandas de irrigação da cultura do feijoeiro e as datas de plantio mais propícias na bacia dos Rios do Leste.

\section{MATERIAL E MÉTODOS}

A bacia dos Rios do Leste situa-se na zona tropical do Hemisfério Sul, entre os paralelos 16 e $20^{\circ}$ de latitude e os meridianos 39 e $42^{\circ}$ de longitude oeste, cobrindo uma área, entre os Estados de Minas Gerais, Espírito Santo e Bahia, de aproximadamente $66.500 \mathrm{~km}^{2}$. No presente estudo, foram utilizadas séries históricas de dados diários de precipitação de 48 estações pluviométricas pertencentes à Agência Nacional de Energia Elétrica (ANEEL), com média de 35 anos de dados e períodos variando de 1930 a 1997 . Foram utilizados, ainda, séries de dados meteorológicos de nove estações climatológicas do Instituto Nacional de Meteorologia (INMET). A seleção da bacia dos Rios do Leste para a simulação do sistema computacional deu-se em virtude da disponibilidade de dados que a mesma apresentava.

O sistema computacional DEMANDAsis foi desenvolvido seguindo-se a metodologia de programação modulada. O DEMANDAsis é composto por vários bancos de dados, utilizados para armazenar as informações referentes ao clima, às características agronômicas das culturas, às estações climatológicas e às características das localidades a serem analisadas.

Para simulação das necessidades hídricas das culturas neste estudo foi utilizada a cultura do feijoeiro, dada a grande importância econômico-social que a mesma representa no cenário nacional, somado à fácil disponibilidade de dados agronômicos dessa cultura. $\mathrm{O}$ ciclo da cultura do feijoeiro foi simulado considerando-se o plantio diário ao longo do ano e se usando o programa computacional DEMANDAsis. Foram utilizados três tipos de solo na simulação, aqui representados pelas texturas: grossa, média e fina, correspondentes às disponibilidades total de água de 0,$6 ; 1,2 ; 1,8 \mathrm{~mm} \mathrm{~cm}^{-1}$. O balanço de água na zona radicular da cultura no DAMANDAsis, utiliza, como referencial, o teor de umidade no limite superior de retenção de água no solo, conforme a Eq. 1:

$$
\mathrm{Da}_{\mathrm{i}}=\mathrm{Da}_{\mathrm{i}-1}+\mathrm{ETc}_{\mathrm{i}}-\operatorname{Prec}_{\mathrm{i}}-\operatorname{Irr}_{\mathrm{i}}+\mathrm{Exc}_{\mathrm{i}}
$$

em que:

$\mathrm{Da}_{\mathrm{i}}$ - déficit de água no período $\mathrm{i}, \mathrm{mm}$

$\mathrm{Da}_{\mathrm{i}-1}$ - déficit de água no período anterior a $\mathrm{i}, \mathrm{mm}$

$\mathrm{ETc}_{\mathrm{i}}$ - evapotranspiração da cultura no período i, $\mathrm{mm}$

Prec $_{i}$ - precipitação pluvial no período i, mm

$\operatorname{Irr}_{\mathrm{i}} \quad$ - irrigação no período $\mathrm{i}, \mathrm{mm}$

Exc $_{\mathrm{i}}$ - excesso hídrico no período i, mm.

O déficit máximo de água, em relação à capacidade de campo que o solo poderia alcançar, foi definido pela capacidade real de água no solo, expressa pela Eq. 2:

$$
\mathrm{CRA}=\frac{(\mathrm{Cc}-\mathrm{Um})}{10} \cdot \mathrm{da} \cdot \mathrm{Z}
$$

em que:

CRA - capacidade real de água no solo, $\mathrm{mm}$

Cc - teor de umidade do solo à capacidade de campo $\%$ em peso

Um - teor de umidade mínima no solo correspondente ao fator de disponibilidade hídrica para a cultura, $\%$ em peso

da - densidade do solo, $\mathrm{g} \mathrm{cm}^{-3}$

$\mathrm{Z}$ - profundidade do sistema radicular, $\mathrm{cm}$.

A evapotranspiração da cultura foi calculada usando-se a metodologia proposta por Doorenbos \& Pruitt (1977) que relaciona a evapotranspiração de referência (ETo) com um coeficiente da cultura (Kc), de acordo com a Eq. 3:

$$
\mathrm{ETc}_{\mathrm{i}}=\mathrm{ETo}_{\mathrm{i}} \cdot \mathrm{Kc}_{\mathrm{i}} \cdot \mathrm{ks}_{\mathrm{i}}
$$

em que:

$\mathrm{ETo}_{\mathrm{i}}$ - evapotranspiração de referência para o período i, mm

$\mathrm{Kc}_{\mathrm{i}}$ - coeficiente de cultura para o período i, adimensional

$\mathrm{ks}_{\mathrm{i}}$ - coeficiente de eficiência de umidade do solo para o período i, adimensional.

A evapotranspiração de referência no DEMANDAsis pode ser determinada por vários métodos, dependendo da disponibilidade de dados climáticos. $\mathrm{O}$ coeficiente de umidade do solo ( $\mathrm{ks}_{\mathrm{i}}$ ), que expressa o efeito do estresse hídrico causado pela diminuição do teor de umidade do solo, foi calculado pela função logarítmica expressa pela razão entre a lâmina atual (LAA) e a capacidade total de água no solo (CTA), recomendada por Bernardo (1995), conforme a Eq. 4.

$$
\mathrm{ks}=\frac{\ln (\mathrm{LAA}+1)}{\ln (\mathrm{CTA}+1)}
$$

O coeficiente de cultura $(\mathrm{Kc})$ foi ajustado por uma equação cúbica relacionada com o ciclo da cultura, com o intuito de se estimar os valores diários de Kc em função dos dias após o plantio, expressando, assim, a variação da evapotranspiração com as fases da cultura. Os valores de Kc foram calculados pela Eq. 5:

$$
\mathrm{Kc}=\mathrm{c}_{0}+\mathrm{c}_{1} \mathrm{x}+\mathrm{c}_{2} \mathrm{x}^{2}+\mathrm{c}_{3} \mathrm{x}^{3}
$$

em que:

$\mathrm{c}_{0}, \mathrm{c}_{1}, \mathrm{c}_{2}$ e $\mathrm{c}_{3}$ - coeficientes da equação de ajuste

$\mathrm{X}$ - dias após o plantio.

A duração do ciclo da cultura foi determinada de acordo com as exigências térmicas, usando-se o conceito de graus-dia.

A precipitação provável ou dependente pode ser definida como a quantidade mínima de precipitação com determinada probabilidade de ocorrência. Neste trabalho foi utilizado um nível de $75 \%$ de probabilidade, valor comumente recomendado para efeito de planejamento agrícola e análise econômica, sugerido por Bernardo (1995), quando se considera o estudo 
de irrigação suplementar. Para estimativa da precipitação cumulativa $\mathrm{P}(\mathrm{Y}<\mathrm{y})$ utilizou-se o modelo de distribuição de probabilidade gama incompleta, sugerido por Thom (1966) expresso pela Eq. 6:

$$
\mathrm{P}(\mathrm{Y} \leq \mathrm{y})=\mathrm{Ps}+\mathrm{Pc} \mathrm{G}(\mathrm{Y} \leq \mathrm{y})
$$

em que:

Ps - probabilidade de ocorrência de períodos sem chuva

Pc - probabilidade de chover no período

$\mathrm{G}(\mathrm{Y} \leq \mathrm{y})$ - densidade de distribuição gama (Eq. 7):

$$
\mathrm{G}(\mathrm{Y} \leq \mathrm{y})=\frac{1}{\Gamma(\alpha) \beta^{\alpha}} \int_{0}^{\mathrm{y}} \mathrm{Y}^{\alpha-1} \mathrm{e}^{-\mathrm{Y} / \beta} \mathrm{dY}
$$

Para $Y, \alpha, \beta$ e $\Gamma(\alpha)>0$

em que:

$\mathrm{G}(\mathrm{Y} \leq \mathrm{y})$ - probabilidade de ocorrência de uma quantidade de chuva igual ou inferior a y

Y - variável aleatória, contínua e independente

$\alpha$ - parâmetro de forma

$\beta$ - parâmetro de escala da variável aleatória $Y$

$\Gamma(\alpha)$ - função matemática gama

y - valor de precipitação que tem probabilidade acumulada

$\mathrm{G}(\mathrm{Y})$ de ocorrer.

A precipitação provável ou dependente pode ser calculada pela seguinte expressão:

$$
\mathrm{P}_{\mathrm{p}}=1-\mathrm{P}(\mathrm{Y}<\mathrm{y})
$$

Na estimativa dos parâmetros de forma $(\alpha)$ e de escala $(\beta)$ utilizou-se o método da máxima verossimilhança sugerido por Thom (1966). Como a Eq. 7 não tem solução imediata, a estimativa dos valores de chuva foi obtida pelo desenvolvimento em série, por meio da Eq. 9:

$$
G(t)=\frac{t^{\alpha}}{\alpha \Gamma(\alpha) e^{t}} F(\alpha, t)
$$

em que:

$$
\mathrm{F}(\alpha, \mathrm{t})=1+\frac{\mathrm{t}}{\alpha+1}+\frac{\mathrm{t}^{2}}{(\alpha+1)(\alpha+2)}+\frac{\mathrm{t}^{3}}{(\alpha+1)(\alpha+2)(\alpha+3)}+\ldots
$$

A probabilidade de ocorrência de um valor de chuva menor ou igual a $\mathrm{Y}$ é dada por $\mathrm{G}(\mathrm{t})$, em que $\mathrm{t}=\mathrm{Y} / \beta$. Para estimativa da quantidade de chuva $\mathrm{Y}$, a um determinado valor de probabilidade, Pr, determina-se o valor de t, na Eq. 9, que satisfaça a igualdade $G(t)-\operatorname{Pr}=0$. Para esse fim, utilizou-se o algoritmo de Newton-Raphson, segundo a Eq. 11:

$$
\mathrm{t}_{\mathrm{iri}}=\mathrm{t}_{\mathrm{i}}-\frac{\frac{\alpha \Gamma(\alpha) \mathrm{e}^{\mathrm{t}_{\mathrm{i}}}}{\mathrm{f}} \mathrm{F}\left(\alpha, \mathrm{t}_{\mathrm{i}}\right)-\mathrm{P}_{\mathrm{r}}}{\frac{\mathrm{t}_{\mathrm{i}}^{\alpha-1}}{\Gamma(\alpha) \mathrm{e}^{\mathrm{t}_{\mathrm{i}}}}}
$$

O excesso de água na zona radicular ocorrerá quando a quantidade de água da chuva ou irrigação proporcionar uma umidade superior ao teor de umidade da capacidade de campo. Essa porção de água em excesso é considerada como perda por percolação profunda.

Na simulação e a partir da integração dos componentes do balanço de água no solo, verificou-se a necessidade de irrigação ao longo do ciclo da cultura, caso em que é simulada a aplicação de uma irrigação suficiente para elevar o conteúdo de água ao limite superior de retenção de água no solo, com base no critério de manejo da lâmina de irrigação mínima requerida através do fator de disponibilidade hídrica para a cultura.

O sistema analisa os diferentes turnos de rega ao longo do ciclo simulado e elege o menor turno de rega para ser usado como parâmetro fixo para uma nova simulação de irrigação, para a mesma data de plantio. Nessa nova simulação, a lâmina total de irrigação suplementar do ciclo é distribuída ao longo do turno de rega. O sistema elege, então, a lâmina máxima de irrigação suplementar aplicada no turno de rega fixo que, dividida pelo valor do turno de rega, corresponde à demanda máxima diária de irrigação suplementar.

A época de plantio foi definida em função da data de plantio em que se verificou maior disponibilidade de água para a cultura durante seu ciclo, de forma a minimizar o uso da irrigação suplementar. Na espacialização das demandas de irrigação total e suplementar, bem como das épocas de plantio, utilizou-se um Sistema de Informações Geográficas através do software IDRISI.

As informações necessárias para executar o programa são disponibilizadas em bancos de dados, padrão dbf, tornando seu manuseio simples para o usuário, necessitando de poucos dados de entrada para executar uma análise, uma vez que essas informações foram introduzidas previamente em módulos diferentes.

O DEMANDAsis está dividido em quatro módulos principais: CADASTRAR, ANÁLISES, UTILITÁRIOS e ENCERRAR. Na Figura 1 tem-se a tela inicial do programa.

$\mathrm{O}$ módulo CADASTRAR possui rotinas relativas à manipulação de bancos de dados, permitindo que sejam feitas inclusões, consultas, alterações e exclusões nos bancos de dados das localidades, estações climatológicas e culturas.

As características agronômicas das culturas são introduzidas no módulo CADASTRAR $\backslash$ culturas\incluir, onde são informados o nome da cultura, variedade, profundidade efetiva do sistema radicular, ciclo da cultura (anual ou perene),

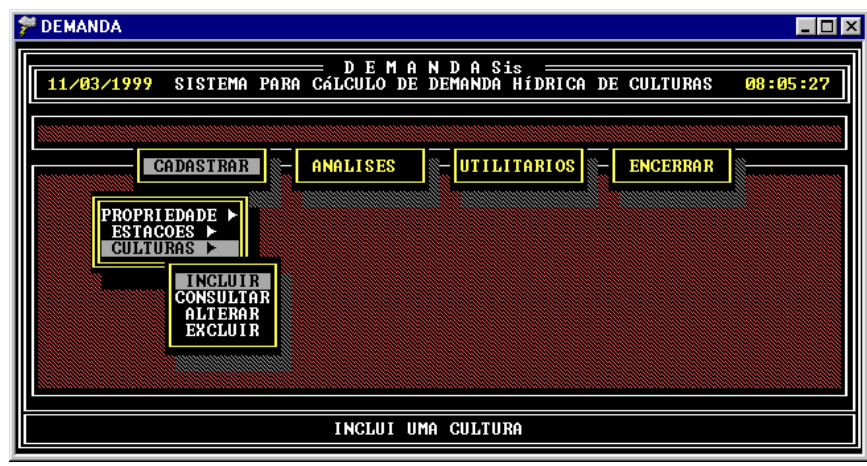

Figura 1. Tela de abertura do programa DEMANDAsis, apresentando as opções do módulo CADASTRAR 
grupo da cultura (legumes, verduras, frutas e forrageiras), temperaturas basal e máxima da cultura, desenvolvimento do ciclo da cultura (graus-dia ou dias), coeficientes da cultura (Kc) e dias para ocorrência da colheita (Figura 2).

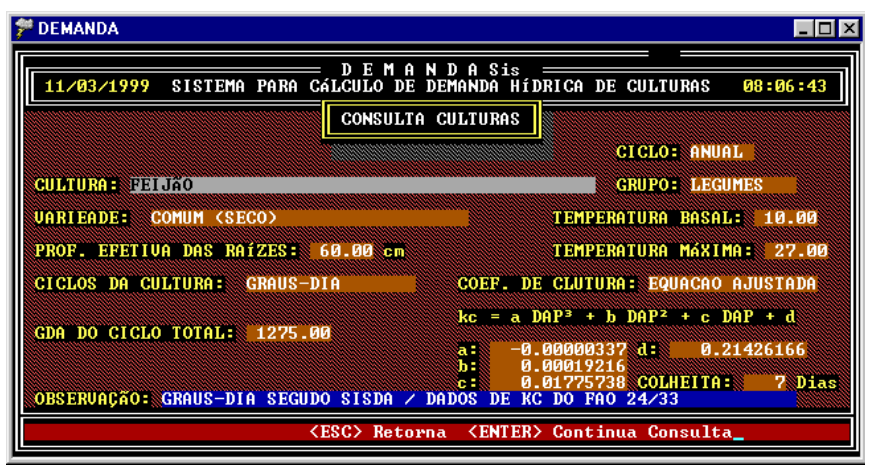

Figura 2. Tela do DEMANDAsis explicitando as informações necessárias para fazer o cadastro das características agronômicas das culturas

O cadastro do grupo a que pertence a cultura, selecionará o fator de disponibilidade hídrica que será usado para definir o teor mínimo de umidade do solo, correspondente à fração do total de água disponível que a cultura pode utilizar sem afetar a sua produtividade. $\mathrm{O}$ valor do fator de disponibilidade hídrica dependerá da maior ou menor sensibilidade da cultura ao déficit de água no solo. Quanto mais resistente for a cultura ao déficit hídrico, maior será o fator de disponibilidade.

O DEMANDAsis considera os coeficientes de cultura fixos para os estádios de desenvolvimento, ou ajustados a uma equação cúbica. A utilização desta última opção procura suavizar a curva de Kc ao longo dos estádios de crescimento da cultura, fornecendo um valor diário de Kc (Figura 3).

No módulo ANÁLISES, podem ser obtidas determinações de evapotranspiração de referência, precipitação provável, demanda de irrigação e simulação de plantio. Os resultados das análises são obtidos para as localidades previamente cadastradas no sistema, utilizando-se os dados das estações climatológicas do INMET e da ANEEL, além dos dados das culturas cadastradas. Durante uma análise de determinada localidade, verifica-se a existência de estação climatológica; caso essa estação não exista, o sistema efetuará uma busca no banco de dados e selecionará a estação mais próxima da

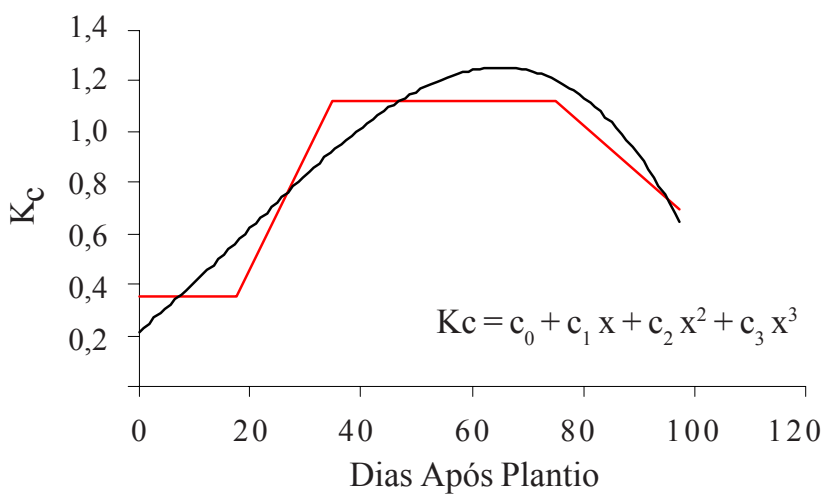

Figura 3. Curvas de fixo e ajustado pela equação cúbica localidade a ser analisada, cujo procedimento é feito tanto nas estações do INMET como nas estações da ANEEL.

Uma análise de plantio pode ser efetuada a partir das informações constantes nos bancos de dados do sistema, selecionando-se a localidade, cultura, método para cálculo da ETo, probabilidade para o cálculo da precipitação provável, período de agrupamento de dados de chuva, datas inicial e final para simulação e intervalos para as simulações de plantio.

A Figura 4 ilustra uma tela com as informações necessárias para uma simulação de plantio da cultura.

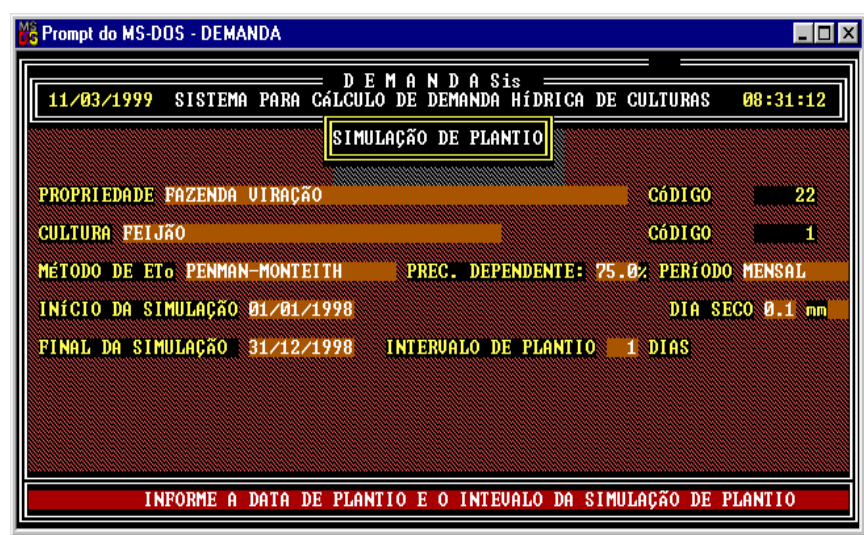

Figura 4. Tela de simulação de plantio do programa DEMANDAsis ilustrando os dados necessários para a análise

A partir do balanço diário de água no solo, o programa gera, como saída, as demandas de irrigação suplementar no ciclo da cultura, precipitação no ciclo, duração do ciclo, turno de rega e a época de plantio, que oferece maior oferta de água ao ciclo da cultura. A Figura 5 apresenta uma tela de saída dos resultados de uma análise de simulação de plantio.

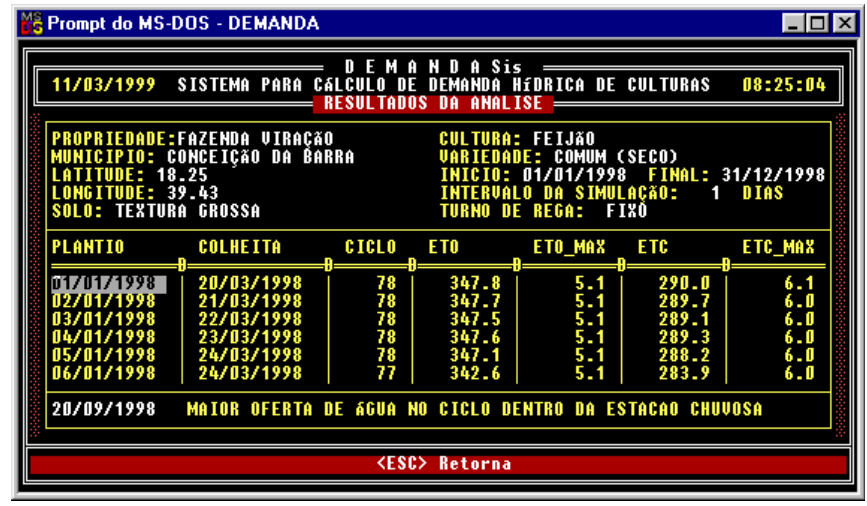

Figura 5. Tela de saída com parte dos resultados da análise de plantio

A época de plantio, em que se verifica maior oferta de água no ciclo da cultura, é selecionada dentro do período chuvoso. A definição do período em que se concentra a estação chuvosa é baseada na metodologia empregada por Frère \& Popov (1979), segundo a qual o início da estação chuvosa ocorre a partir da semana em que a precipitação atinge $50 \%$ da evapotranspiração de referência e não são registrados períodos secos na semana seguinte. Analogamente, o término da estação chuvosa ocorre 


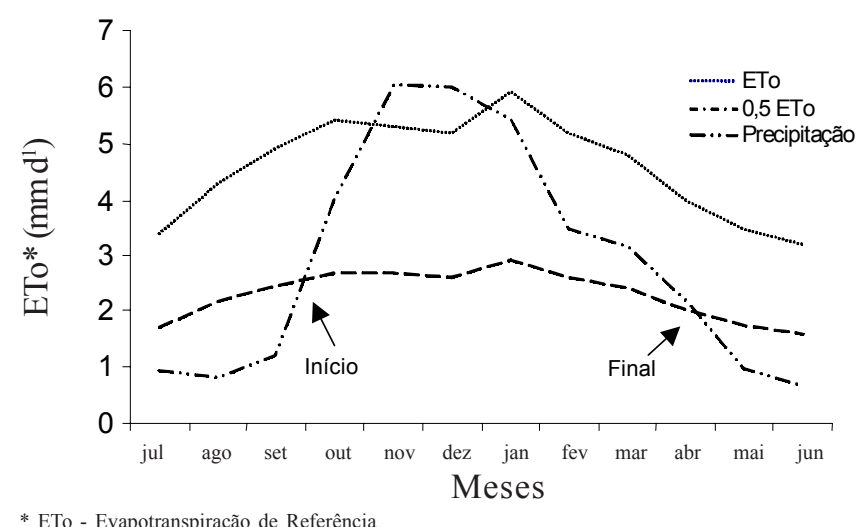

Figura 6. Indicação do início e fim da estação chuvosa usada para indicar a época de plantio que apresenta maior disponibilidade de água no ciclo da cultura

na semana em que a precipitação se reduz à metade da ETo. Na Figura 6 apresenta-se uma ilustração desse procedimento.

O módulo UTILITÁRIO apresenta as opções para efetuar cópia de segurança dos bancos de dados do sistema e sua restauração, utilização do software REF-ET (Allen, 1991) e sistema de senhas do programa. O módulo ENCERRAR efetua o fechamento do programa DEMANDAsis.

A demanda máxima diária de irrigação suplementar ao longo do ciclo pode ser utilizada para elaboração de estratégias de planejamento da implantação de sistemas de irrigação, baseados em lâminas suplementares, ou seja, aproveitando-se ao máximo as precipitações que ocorrem durante a estação chuvosa. O dimensionamento do sistema de irrigação pode, então, ser feito a partir da lâmina máxima de irrigação suplementar resultante da simulação de plantio. A Figura 7 ilustra a ocorrência do valor máximo de irrigação suplementar no ciclo da cultura para diferentes datas de plantio ao longo do ano. O menor valor de demanda de irrigação suplementar acumulado ao longo do ciclo em função da época de plantio pode ser usado para indicar a época propícia para o plantio em que se verifica menor consumo de irrigação suplementar.

\section{RESULTADOS E DISCUSSÃO}

A variação espacial das demandas de irrigação total e suplementar foi analisada considerando-se a época mais crítica para o plantio do feijão, de modo que a cultura não sofresse nenhum déficit de água durante seu ciclo. Na Figura 8 está ilustrada a variação espacial da evapotranspiração de referência (ETo) máxima diária observada ao longo do ano na bacia dos Rios do Leste. Verifica-se predomínio da ETo entre 5,2 e $5,5 \mathrm{~mm} \mathrm{~d}^{-1} \mathrm{em} 66 \%$ da área da bacia, desde a porção sudeste até o extremo nordeste. Os menores valores de ETo $\left(4,5 \mathrm{~mm} \mathrm{~d}^{-1}\right)$ ocupam a porção oeste da bacia, com aproximadamente $11 \%$ da área.

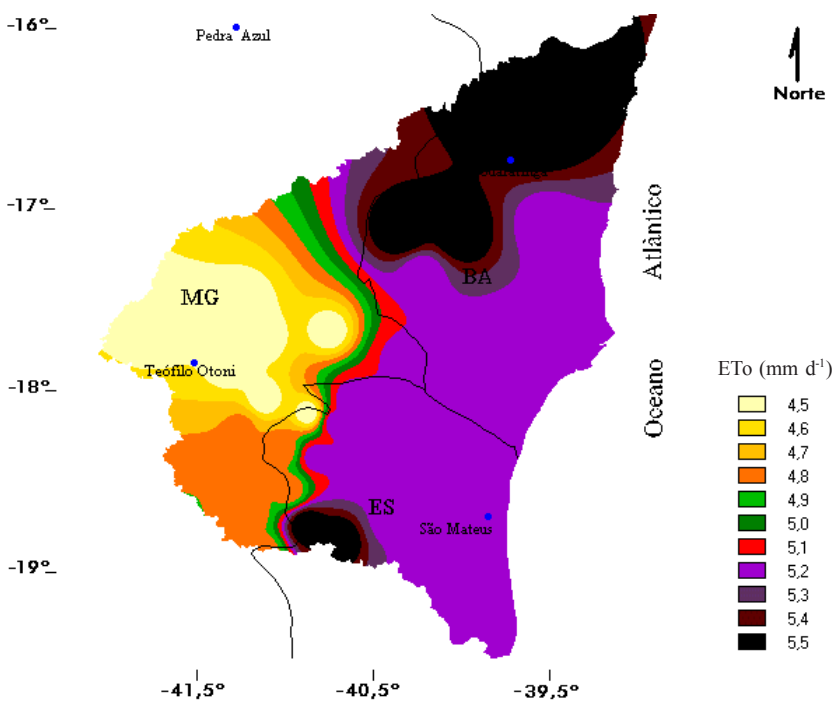

Figura 8. Variação espacial da evapotranspiração de referência (ETo) máxima diária $\left(\mathrm{mm} \mathrm{d}^{-1}\right)$, observada ao longo do ano na bacia dos Rios do Leste

Na Figura 9A está ilustrada a variação espacial da demanda de irrigação total para a cultura do feijão, cultivada em um solo de textura média. Os maiores valores de demanda de irrigação

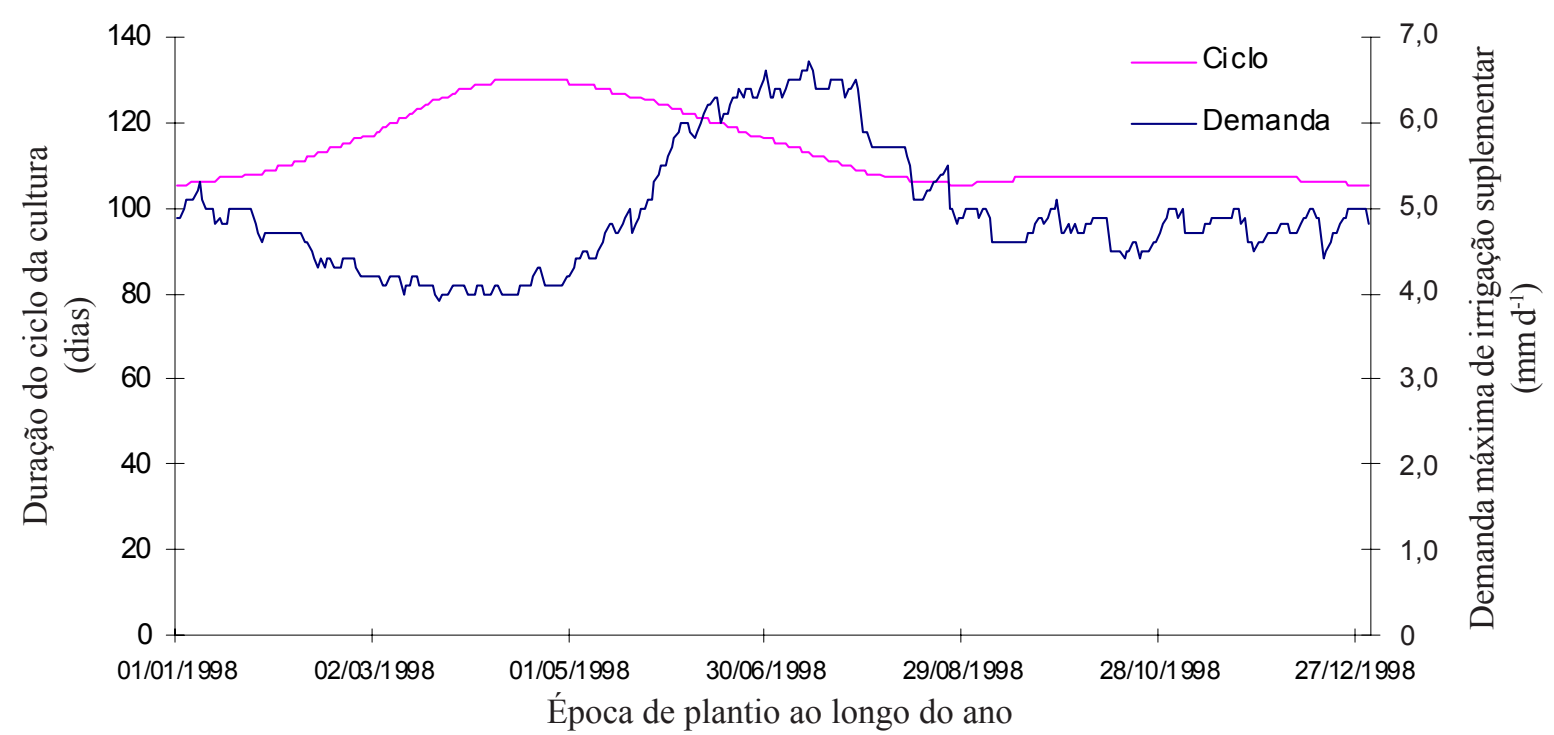

Figura 7. Demanda máxima de irrigação suplementar e duração do ciclo da cultura em função da época de plantio ao longo do ano 
A.

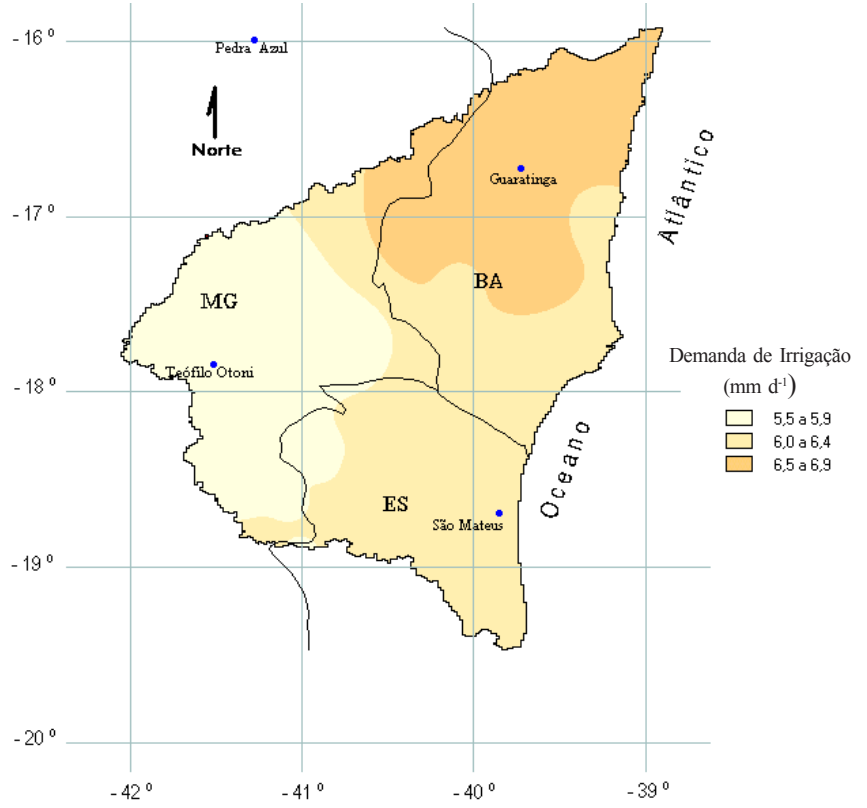

B.

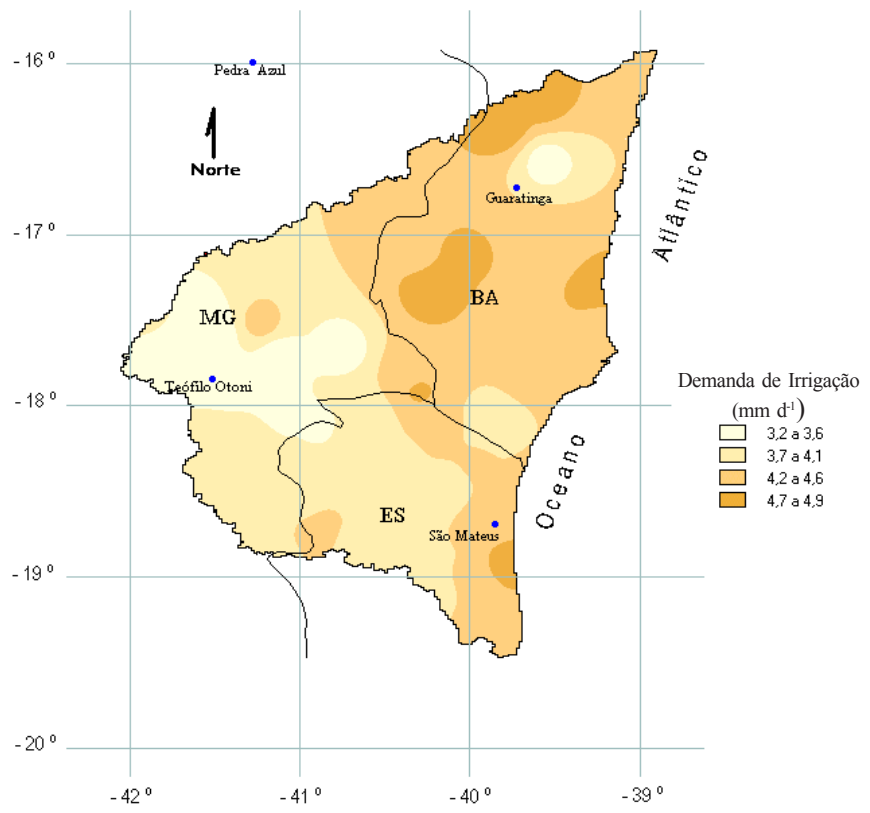

Figura 9. Demanda de irrigação total (A) e suplementar (B), em mm d ${ }^{-1}$, para a cultura do feijão, cultivada em solo de textura média, na bacia dos Rios do Leste

total ocorrem entre 6,5 e $6,9 \mathrm{~mm} \mathrm{~d}^{-1}$, na porção nordeste e em pequenas áreas ao sul da bacia. Esses valores ocupam, em média, 28\% da área de toda a bacia. A maior porção, entretanto, com cerca de $46 \%$, é atendida com lâminas de irrigação total entre 6,0 e $6,4 \mathrm{~mm} \mathrm{~d}^{-1}$. Os menores valores de irrigação total concentram-se na porção oeste da Bacia.

Verificou-se, analisando a Tabela 1 que, praticamente, não houve variação na demanda de irrigação total com a mudança do tipo de solo, concluindo-se, então, apesar das capacidades de armazenamento de água dos solos serem diferentes, os valores máximos de necessidades hídricas da cultura são aproximadamente iguais nas diferentes localidades ao longo da bacia. Neste caso, a demanda de irrigação total foi influenciada, principalmente, pelas condições climáticas dessas localidades.

Tabela 1. Percentagem de área ocupada por classe de demanda de irrigação total para a cultura do feijão cultivada em solos de texturas grossa, média e fina, na bacia dos Rios do Leste

\begin{tabular}{cccc}
\hline & \multicolumn{3}{c}{ Área Ocupada - \% } \\
\cline { 2 - 4 } Classes de & $\begin{array}{c}\text { Textura } \\
\text { Gemanda }\left(\mathrm{mm} \mathrm{d}^{-1}\right)\end{array}$ & $\begin{array}{c}\text { Textura } \\
\text { Gédia }\end{array}$ & $\begin{array}{c}\text { Textura } \\
\text { Fina }\end{array}$ \\
\hline $5,5-5,9$ & 25 & 29 & 26 \\
$6,0-6,4$ & 46 & 43 & 48 \\
$6,5-6,9$ & 29 & 28 & 26 \\
\hline
\end{tabular}

Com a contribuição da precipitação pluvial, aqui representada pela precipitação provável, verificou-se redução na demanda de irrigação, nos três tipos de solo, resultando em menores valores de lâminas de irrigação suplementares para a cultura do feijão. Na Figura 9B tem-se a variação espacial da demanda de irrigação suplementar, considerando-se um solo de textura média. Concordando com a ocorrência da demanda de irrigação total, a suplementar apresenta seus menores valores na porção oeste da bacia; contudo, verificou-se redução significativa da demanda de irrigação na porção Nordeste da bacia, influenciada pelo bom aporte de água das chuvas durante o ciclo da cultura, uma vez que nessa região se concentram altas demandas de irrigação total.

Considerando-se que a precipitação pluvial indica alta variação espacial, a variação espacial da demanda de irrigação suplementar torna-se também evidente, o que se pode verificar ao longo da bacia. Em média, $41 \%$ da área da bacia são atendidos por lâminas de irrigação suplementar para o feijoeiro entre 4,1 e 4,9 $\mathrm{mm} \mathrm{d}^{-1}$, independentemente do tipo de solo, concentrando-se desde o extremo sudeste até as regiões norte e nordeste. Os menores valores, entre 3,1 e $3,9 \mathrm{~mm} \mathrm{~d}^{-1}$, representam, em média, $16 \%$ da área da bacia.

Salienta-se que a evidente redução na demanda de irrigação suplementar em regiões onde a demanda total é elevada se deve à contribuição da chuva, sendo importante sua consideração na estimativa das necessidades hídricas para fins de dimensionamento de sistemas de irrigação.

As épocas de plantio podem ser usadas como subsídio para auxiliar o planejamento das atividades agrícolas, baseadas em práticas de irrigação suplementar. A época de plantio na estação chuvosa, quando há maior disponibilidade de água para a cultura, implica em um consumo menor de irrigação suplementar, sendo também importante sob a ótica do uso racional dos recursos hídricos na agricultura.

$\mathrm{Na}$ Figura 10 é ilustrada a variação espacial das épocas de plantio em que se verifica maior disponibilidade de água, resultante do aporte das chuvas, no ciclo da cultura do feijoeiro, cultivada em solo de textura média. Observa-se, nessa figura, predomínio do plantio de feijão entre os dias 5 e 19 de outubro, em $53,3 \%$ da área da bacia seguido dos dias entre 20 de outubro e 3 novembro, ocupando uma área de $34,3 \%$ da bacia. Estas 


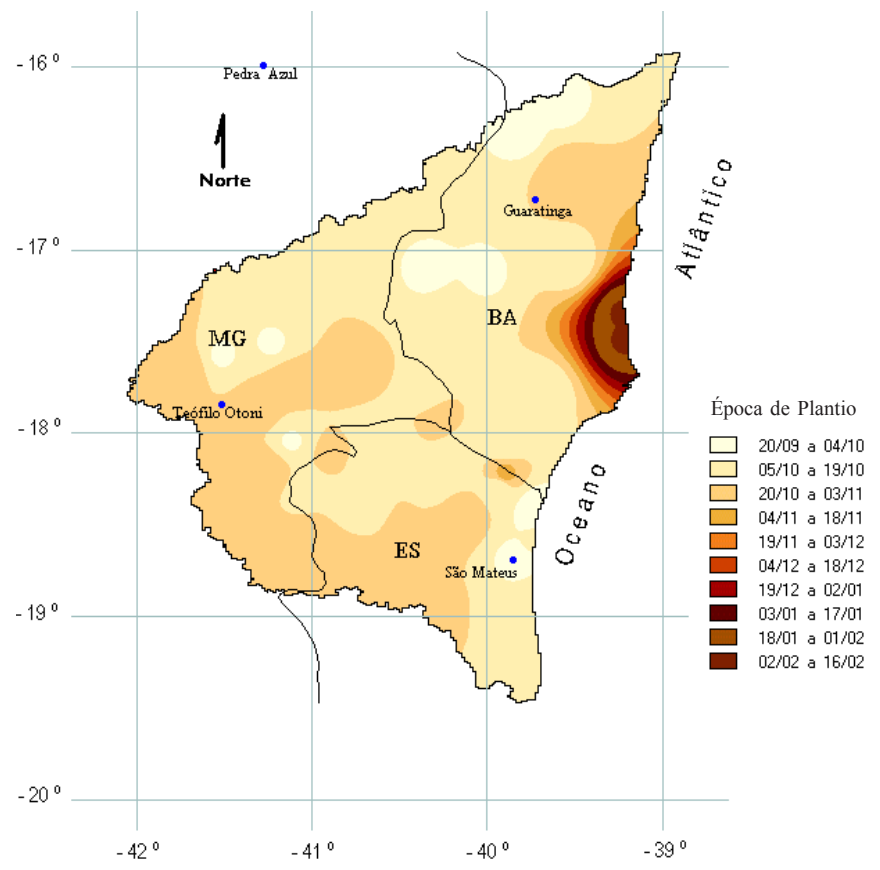

Figura 10. Época de plantio do feijão cultivado em solo de textura média, considerando-se a maior disponibilidade de água de chuva durante o ciclo da cultura, na bacia dos Rios do Leste

datas correspondem ao início propriamente dito da estação chuvosa, que proporciona grande aporte de água ao longo do ciclo da cultura, na maioria das localidades da bacia; destacase, porém, a ocorrência de pequenas áreas a leste da bacia, onde a indicação da época de plantio tende a atrasar-se para o mês de dezembro, devido, possivelmente, ao atraso do início da estação chuvosa, que na bacia ocorre no sentido do oeste para o leste. Essas épocas de plantio devem ser complementadas com outras informações locais para melhor definição da época de plantio do feijão, uma vez que este estudo se baseou apenas no melhor aproveitamento da água da chuva, para essa cultura.

\section{CONCLUSÕES}

1. As lâminas de irrigação total entre $6,0 \mathrm{e} 6,4 \mathrm{~mm} \mathrm{~d}^{-1}$ atendem às necessidades da cultura do feijão, em $46 \%$ da bacia, independentemente do tipo de solo.
2. Cerca de $41 \%$ da área da bacia podem ter as necessidades de irrigação suplementar do feijoeiro atendidas com lâminas entre 4,1 e $4,9 \mathrm{~mm} \mathrm{~d}^{-1}$.

3. A época de plantio predominante para o feijoeiro em $53,3 \%$ da área da Bacia ocorre entre os dias 5 e 19 de outubro.

4. O sistema computacional, DEMANDAsis, mostrou-se útil para determinação da demanda de irrigação e simulação de épocas de plantio de culturas agrícolas, podendo ser usado para o planejamento de atividades agrícolas.

\section{LITERATURA CITADA}

Allen, R. G. Reference evapotranspiration calculator. Version 2.1. Logan: Utah State University, 1991.36p.

Bernardo, S. Manual de irrigação. Viçosa: UFV, Imprensa Universitária, 1995. 657p.

Costa, L. C.; Mantovani, E. C.; Soares, A. A. Leal, B G. SISDA: A decision support system for agriculture in Brazil. In: Information technology as a tool to assess land use options in space and time. Proceedings of International Workshop. Lima: 1997. p.33-39.

Doorenbos, J.; Pruitt, W. 0. Guidelines for predicting crop water requirements. Rome: FAO, 1977. 179p. Irrigation and Drainage Paper, 24

Faria, R. A. Demanda de irrigação suplementar no Estado de Minas Gerais. Viçosa: UFV, Imprensa Universitária, 1998. 80p. Dissertação Mestrado

Frère, M.; Popov, G. F. Agrometeorological crop. Monitoring and forescasting. Rome: FAO, 1979. Plant Production and Protection Paper, 77

Marouelli, W. A. Análise de distribuição das probabilidades de chuva, visando ao manejo de irrigação suplementar. Viçosa: UFV, Imprensa Universitária, 1993. 123p.

Reichardt, K.; Timm, L.C. Solo, planta e atmosfera: conceitos, processos e aplicações. Barueri. Ed. Manole Ltda., 2004. 478p.

Smith, M. CROPWAT: a computer program for irrigation planning and management. Rome: FAO Land and Water Development Division, 1992.

Souza, E. F. Modelo computacional aplicado ao manejo e planejamento da irrigação. Viçosa, MG: UFV, Imprensa Universitária,1993. 65p. Dissertação Mestrado

Thom, H. C. S. Some methods of climatological analysis. Geneva: WMO, 1966. 53p. Technical Note, 81 